\title{
ON THE MEDIAN ANTERIOR CEREBRAL ARTERY AS FOUND AMONG THE INSANE
}

\author{
I. W. BLACKBURN \\ From the Government Hospital for the Insane, Washington, D. C. \\ WITH SIX FIGURES
}

The subject of anomalies of the cerebral arteries among the insane has received considerable attention in the past, especially noteworthy being the article by Bullen in the Journal of Mental Science, volume $36,1890,{ }^{1}$ but unfortunately comparative statistics are meagre. In 1907 I made a study of the conditions of development of the encephalic arteries in 220 consecutive cases of mental diseases, making a comparison with the studies of Windle ${ }^{2}$ in 200 cases of those presumably sane. The results of this comparison seemed to show a decided predominance, in general, of anomalous conditions among the mentally diseased. ${ }^{3}$

In the study above mentioned, being chiefly concerned with the anomalies of the circle of Willis, sufficiently careful studies of other arteries were not made, and as a result, the anomalous vessel which forms the subject of this paper was not as frequently found as subsequent observations show is probably the fact. This artery is found of course among the sane as well as the insane. My studies, however, are based upon the examination of 400 consecutive cases of mental disease examined with special reference to this vessel. In all of the text books of anatomy at my com-

1Bullen. Post mortem Examination of the Brain, etc. Journal of Mental Science, vol. 36, 1890.

2 Windue. On the Circle of Willis. Reports of the Brilish Medical Association, for 1887. New York Medical Journal, vol. 2, 1888, and Journal of Anatomy and Psysiology, 1887-1888.

"Blackburn. Anomalies of the Encephalic Arteries among the Insane. Journal of Comparative Neurology and Psychology, vol. 17, no. 6, 1907. 
mand I have either found no reference to the artery at all, or a mere mention of it, as by Cunningham, as a third anterior cerebral artery sometimes present, or by Quain, as found in 4.5 per cent of cases."

In an article in the Journal of Nervous and Mental Disease, volume 12 , no. 3 , July, 1885 , under the heading, "On a seldom described Artery (Arteria Termatica) etc," Professor Wilder describes the artery and gives it the name of Arteria Termatica, from the place of location and chief distribution in his cases. Professor Wilder thus describes the vessel which he found in a large percentage of human brains examined:

It usually soon divides into a right and left portion which supply respectively the cinerea forming the surface of the triangular area ventrad of the rostrum on either side, and then extend around the genu to the dorsal aspect of the callosum.

In another place in the same paper, he describes its origin, as most frequently from the place of junction of the precerebrals, the pre-communicant being absent, an important observation in connection with the present subject. In some respects most of my cases of this artery have varied somewhat from Wilder's description, being as a rule larger, and following more closely the description of the median anterior cerebral artery as described by Windle, who says,

It passes along the longitudinal fissure for two-thirds of the length of the callosum, and divides into two branches, supplying the opposite surfaces of the hemispheres.

Windle found this artery present in 9 of the 200 cases examined, and as his description of it is unqualified, it may be concluded that most of his cases were of the larger-sized vessels, perhaps more properly named the median anterior cerebral artery, though I have no doubt that Wilder, Windle and $I$ are describing the same vessel.

4UaIn's Anatomy, 1892. Other text books of Anatomy. 
In a typical median anterior cerebral artery, the description is as follows:

The vessel arises from the anterior communicating artery, usually near the middle; curves upward, and in close proximity to the lamina terminalis, around the genu of the callosum, lying close to this body; and at about the middle or at the junction of the anterior two-thirds with the posterior third of the callosum it divides into two nearly equal branches which are distributed to the paracentral lobules and the quadrate lobules of the opposite hemispheres. In the course of the main trunk and the principal branches of the vessel, small and unimportant branches are given off to the lamina terminalis, the callosum, and to the adjoining gyri, but these ultimate branches have not been worked out, and are perhaps relatively unimportant. A large majority of these aberrant vessels have this origin and distribution, though occasionally the origin may be nearer to one anterior cerebral artery than the other. It may even seem to originate from one of these vessels near to the junction with the communicans, or what is still more important for our study, it not infrequently arises from the end of the junction of the two anterior cerebrals when these are fused and the anterior. communicating artery as such is absent.

Differences in the size and distribution of the main branches are occasionally met with; sometimes one branch may be wanting, and the vessel is then distributed to one side only. In the small or undeveloped vessels as those described by Wilder, the branches are all small and irregular, and are sent mainly to the lamina terminalis, the rostrum callosi, and the gyri in theimmediate vicinity. ${ }^{5}$

In an article by Grünbaum and Sherrington in Brain, 1902,

\footnotetext{
${ }^{5} \mathrm{I}$ find that on carefully removing the basal arteries and floating them out in water, often a long, slender, arteria termatica is unexpectedly revealed. This leads me to suspect that arteries of this type are quite frequently present but are undiscovered; probably the percentage of median anterior cerebral arteries might be nearly doubled if careful search were thus made. Whether these arteries are vestigial or reversionary, it is certain that in the majority of instances no such vessel arises from the anterior communicating artery, and that no corresponding vessel is mentioned among the branches of the artery by most anatomists.
} 
"Note on the arterial supply of the Brain in Anthropoid Apes," these observers state:

Among features of human character pertaining to the anthropoid apes, we find one not hitherto recorded, namely the existence in the cerebral arterial supply of a Circulus Willisii resembling that of man. In these highest apes, as in man, an anterior communicating artery quite frequently completes the circulus in front;

and, quoting Parsons, they add:

In all of the lower mammals which I have examined, including the Platyrrhine monkeys, Cercopithecus, etc., I find no anterior communicating artery.

In all of the lower forms of mammals instead of the pair of anterior cerebral arteries, there is but a single azygos vessel, which in its course forward gives off branches to the right and left hemispheres respectively. These observers examined six brains of chimpanzees, and one orang-outang. Of the six chimpanzees, in five the circulus had the human type. In one of these two anterior cerebral trunks were united or fused into a common trunk about four $\mathrm{mm}$. in length. In the orang-outang also the circulus was completed by an anterior communicating artery, and in one of the six chimpanzees there was a single azygos anterior cerebral artery as in the lower mammalian forms. This work, which is in accord with the writer's limited experience, shows that the existence of an azygos vessel in place of the anterior communicating artery and the two anterior cerebrals is the rule in the lower mammals, and that the form found in the higher anthropoid apes and in man is a phylogenous development while it also suggests that in view of the frequency of anomalous forms in the anterior cerebrals, that this phylogeny is as yet unstable.

In these arteries, anomalies of development are by all odds more frequent than in any other sets of vessels. Windle in 200 cases found 8 of fusion, 9 median anterior cerebral arteries, and a large number of anomalies of the anterior communicating artery; in my own 220 cases, fusion of the vessels was found in 7 cases, in 

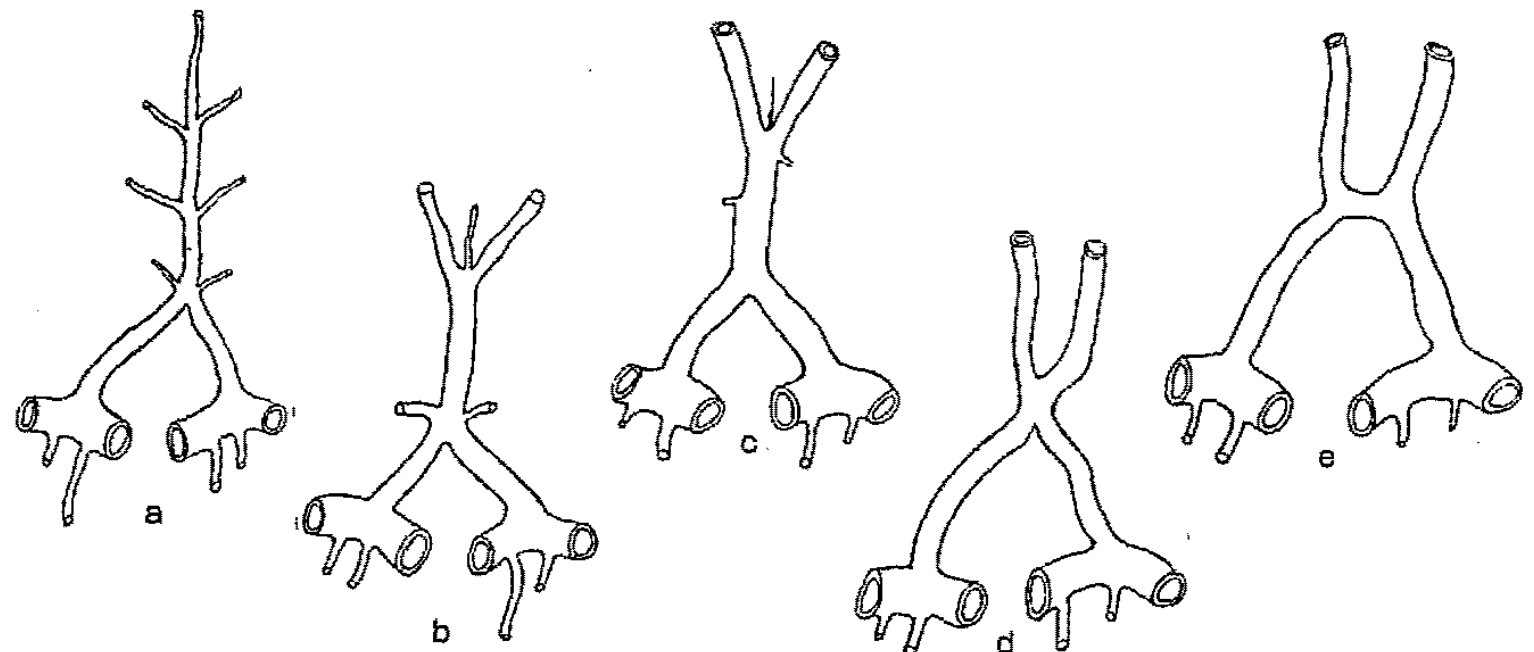
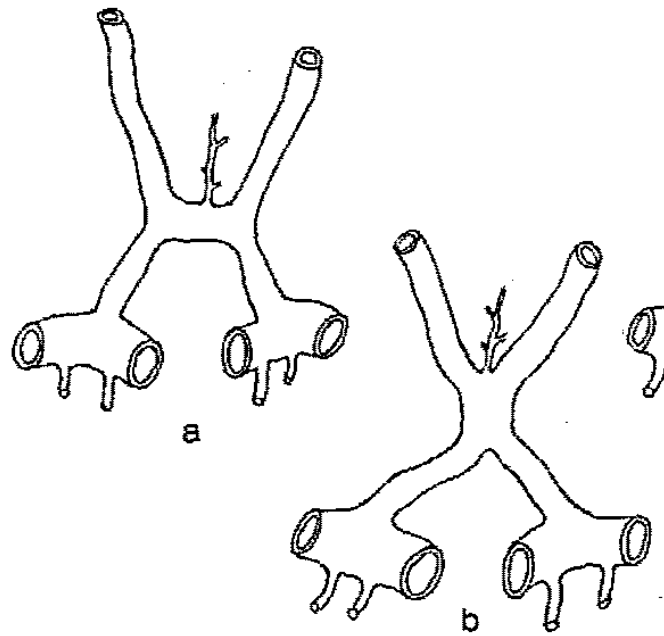

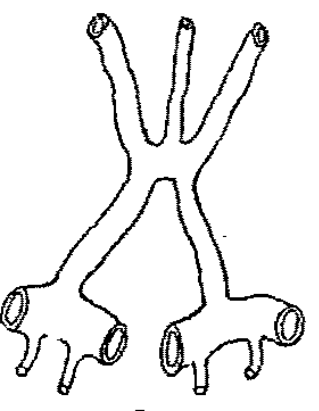

c

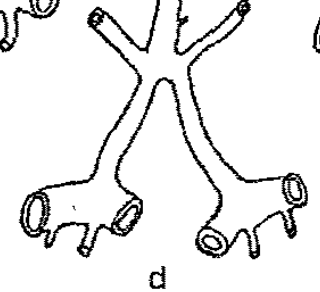

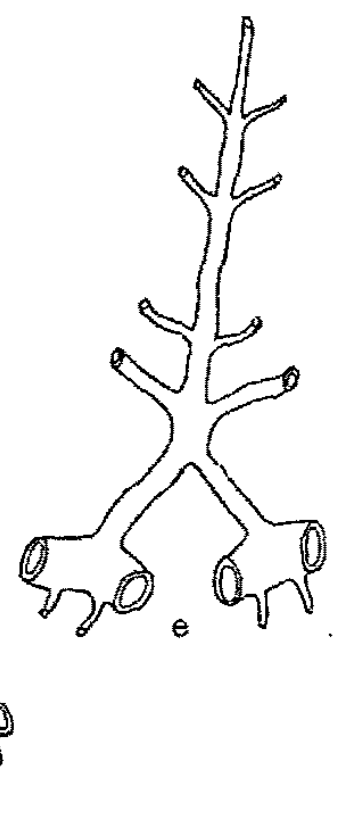

2
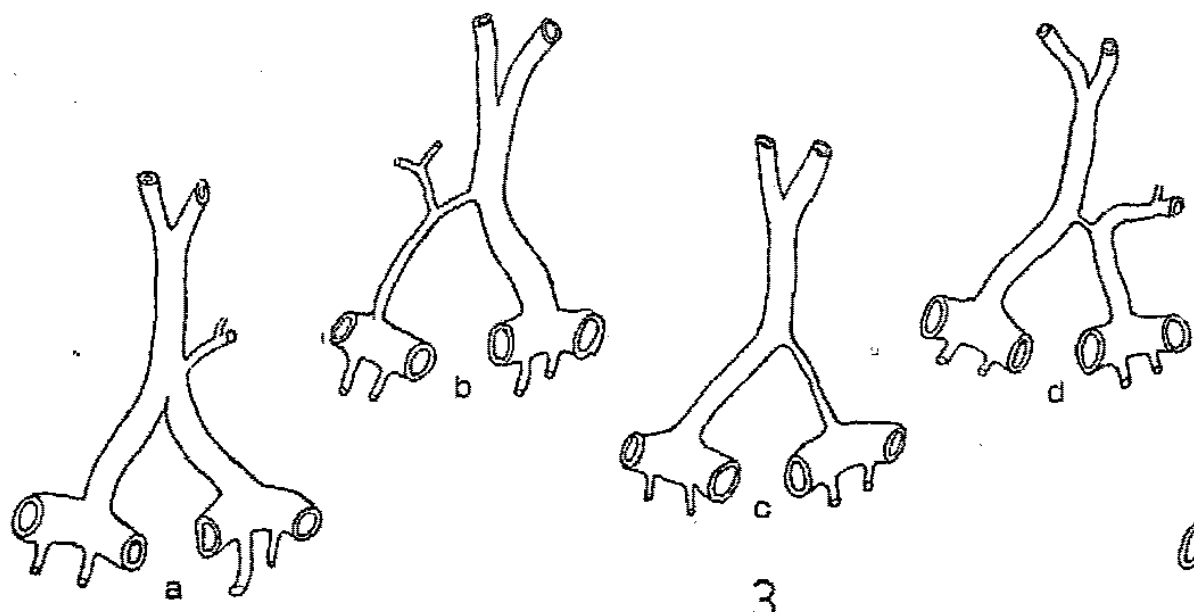

3

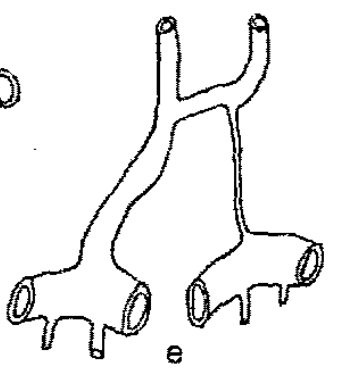

FIg. 1. a-e. Developmental types of the anterior system of cerebral arteries.

FIG. 2. a-c. Reversionary types of the anterior cerebral arteries.

Frg. 3. a-e. Types of anomalies of the anterior cerebral arteries. 
10 the right artery was very small, and the opposite carotid artery sent the blood supply to the two hemispheres through an enlarged anterior communicating artery, and in 6 cases the left artery was the smaller, and the main blood supply came from the right carotid system; in a large percentage of cases, anomalies of the communicans were found. It is possible that in many of the apparent anomalies of the anterior cerebral arteries with disproportion in size of the trunks beyond the anterior communicating artery, the larger vessel may be a partial reversion to the primitive type; that is, a median anterior cerebral unusual only in place of origin. In fact, it is not at all uncommon for the larger of the two trunks to send branches to the mesial surfaces of both hemispheres.

It may then be granted that the lower types are being developed in the phylogeny of the races, and such being the case, reversion to the primitive type may now and then be expected. It has seemed to the writer that the development and reversions might be shown graphically in the accompanying drawings, nearly all of which are drawn from actual specimens. In Fig. 1, a represents the primitive form as met with in the lower mammals; $b$ shows the fusion of the anterior cerebrals with the remnant of the azygos vessel at the end of the junction; $c$ a later stage of the development, with the remnant of the azygos vessel; $d$ shows the shortening of the place of junction, and $e$ shows a fully developed anterior communicating artery. Fig. 2 shows the occasional reversions met with; $a$ gives the type of arteria termatica of Wilder; $b$ gives the type of termatic artery which arises from the end of the short fusion of the two vessels; $c$ shows the most common form of median anterior cerebral artery; $d$, that in which the anomalous artery is the largest of the three, and $e$, the aImost complete reversion to the lower mammalian type; $e$, however, has not actually been seen by the writer, while $d$ is common. ${ }^{6}$

It is suggested by these forms that in the higher phylogenetic development of the brain, the greater size of the frontal lobes has

Quain says: "The two arteries have also been seen united in a single trunk, which runs in the longitudinal fissure, giving off branches to both hemispheres." The writer has recently found one of these vessels, hence the series may be regarded as complete. 
necessitated a development of two anterior lateral branches of the azygos vessel into the two latera! anterior cerebral arteries, and that with this has progressively gone on a shortening of the fusion of the two vessels and an atrophy of the azygos terminal, until finally we find the human type of this vessel, the anterior communicating artery, and the two lateral cerebrals. The fact that we occasionally meet with a medjan vessel, with fusion of

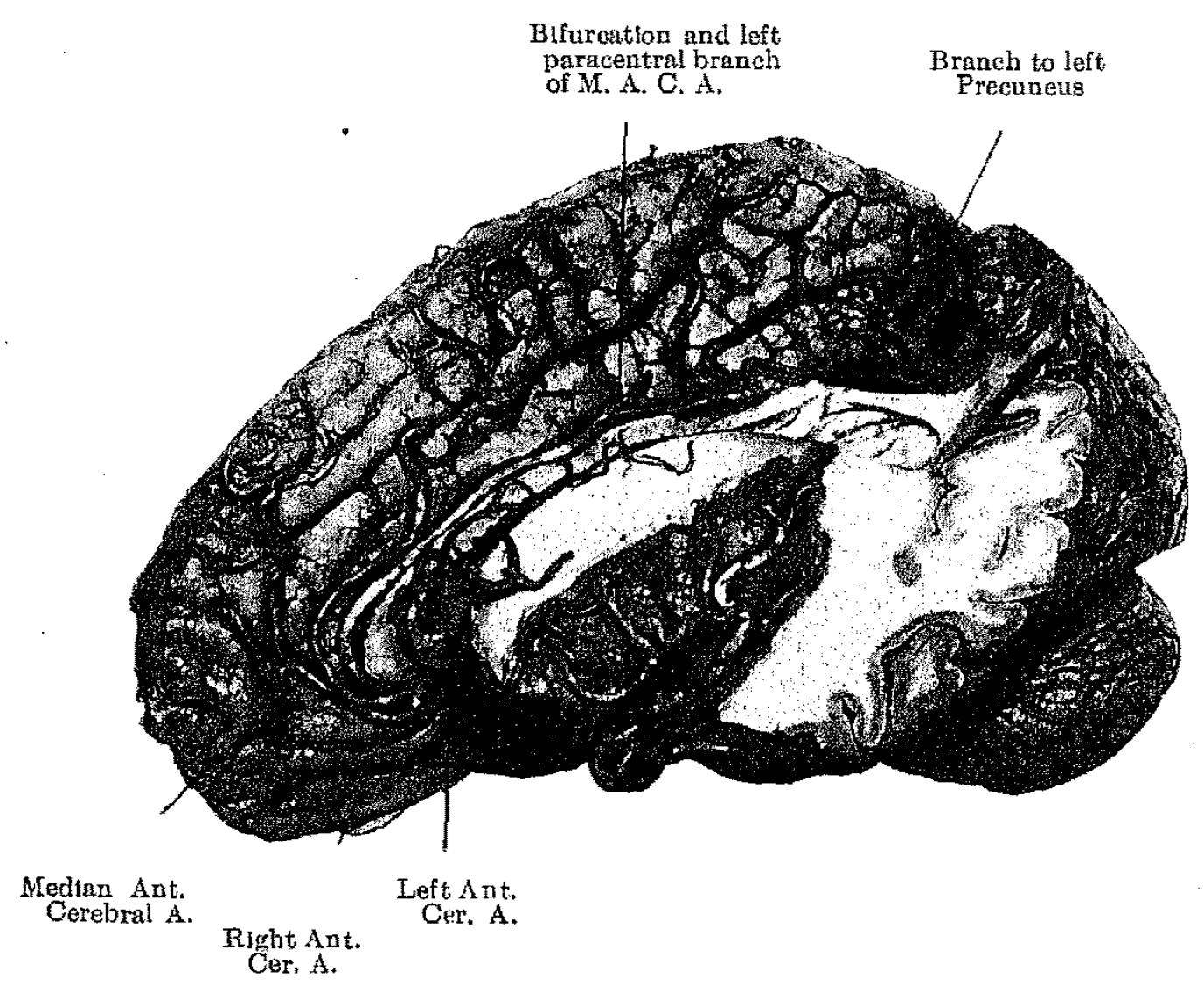

Fig. 4. Photograph of a dissection showing the two lateral anterior cerebral arteries and a large median anterior cerebral artery with a typical distribution.

the two anterior cerebrals, and other anomalies of this set of vessels, I think may be accounted for on the principle of reversions and anomalies so frequently found among the insane.

The median anterior cerebral artery has been found in all forms of mental diseases, possibly a little more frequently in forms of dementia. In 400 cases of mental disease, 42 instances of the abnormal vessel were found; 11 were in senile dementia, 7 in chronic 
dementia, 5 in epileptic dementia, 5 in arteriosclerotic dementia, 4 in paresis, 3 in chronic melancholia, 2 in dementia praecox, and 1 case each in manic-depressive insanity, organic dementia, acute delirious mania,acute mania, and idiocy, Twenty-five of these cases were in white males, 11 in colored males, 4 in colored females and 2 in white females. The disproportion between the cases examined of each color and sex makes this of relatively little value.

I do not see that there can be any special relationship between the mental disease per se and the presence of this anomalous vessel, but on the supervention of arterial diseases some very interesting cerebral conditions might be caused. In most instances, cerebral arterial anomalies are compensated for before the develop-

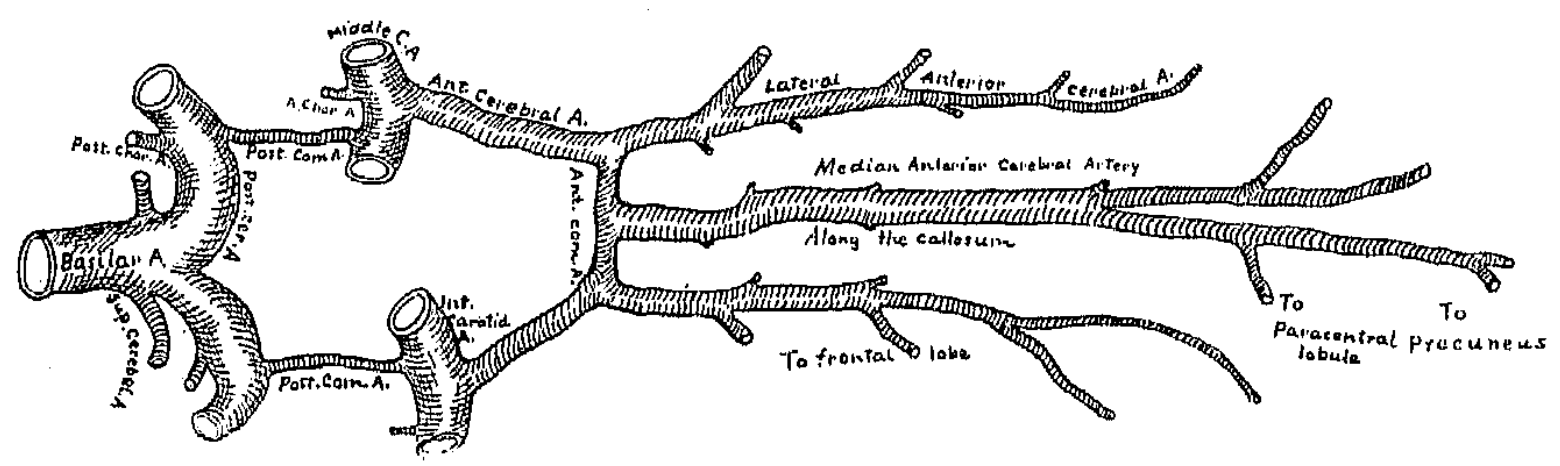

Fra. 5. Diagram of the Circle of Willis with a typical median anterior cerebral artery.

ment of the psychosis, the anomaly being then only indicative of ill development.

In these days of bold operations upon the vessels and even on structures at the base of the brain, it might be well for the surgeon to bear in mind the existence of these anomalies. In fact the main object of the paper of Grünbaum and Sherrington, quoted from above, was to call attention to the surgical relations of the inequalities of cross anastomosis of the circulation in anomalies of this anterior arterial system. Illustrative of these dangers may be mentioned one of my own cases in which thrombosis of the intracranial portion of the carotid artery resulted in death of the 
whole left hemisphere on account of small size and sclerotic obstruction of the anterior communicating artery and the left posterior cerebral artery.

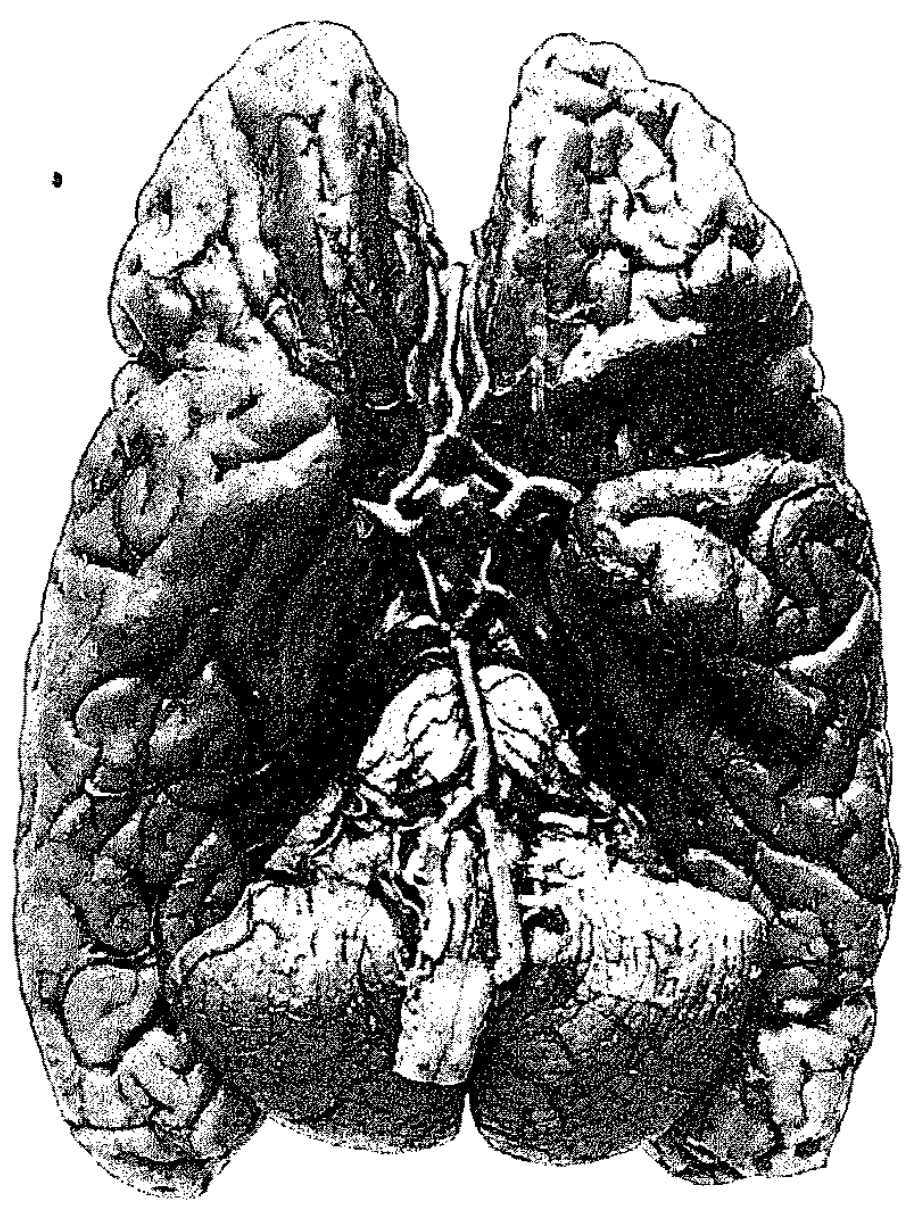

Fig, 6. Photograph of the base of the brain showing the origin of a large median anterior cerebral artery.

The conclusions which $I$ think we may reach with certainty are as follows:

1. There is a gradual development of the lower mammalian form of azygos anterior cerebral artery into the perfect Circulus Willisii of the human type.

2. The frequent variations of this system of vessels suggest instability of ontogeny, and of phylogeny.

3. The anomalies of these arteries together with the presence 
of the median anterior cerebral artery are frequent among the insane.

4. That in keeping with other anomalies of the brain among the insane it is probable that many of these variations are in the direction of reversion to the primitive type, and that it is reasonable that the frequently found arteria termatica is one of these reversions or survivals such as are not uncommon in other organs. 